\title{
DNase-B Antibody Measurement
}

National Cancer Institute

\section{Source}

National Cancer Institute. DNase-B Antibody Measurement. NCI Thesaurus. Code C100463.

The determination of the amount of Dnase-B antibody present in a sample. 